\title{
Ocular manifestations in systemic lupus erythematosus
}

\author{
Sukhum Silpa-archa, ${ }^{1,2,3}$ Joan J Lee, ${ }^{1,2}$ C Stephen Foster ${ }^{1,2,4}$
}

${ }^{1}$ Massachusetts Eye Research and Surgery Institution, Cambridge, Massachusetts, USA

${ }^{2}$ Ocular Immunology \& Uveitis Foundation, Cambridge, Massachusetts, USA

${ }^{3}$ Faculty of Medicine, Department of Ophthalmology, Rajavithi Hospital, College of Medicine, Rangsit University, Bangkok, Thailand

${ }^{4}$ Harvard Medical School, Boston, Massachusetts, USA

\section{Correspondence to} Dr C Stephen Foster, Massachusetts Eye Research and Surgery Institution, 355 Main Street, Five Cambridge Center, 8th Floor, Cambridge, MA 02142, USA:

sfoster@mersi.com

Received 12 January 2015 Revised 4 March 2015 Accepted 4 April 2015 Published Online First 22 April 2015
CrossMark

$$
\begin{aligned}
& \text { To cite: Silpa-archa S, } \\
& \text { Lee JJ, Foster CS. Br J } \\
& \text { Ophthalmol 2016;100: } \\
& \text { 135-141. }
\end{aligned}
$$

\section{ABSTRACT}

Systemic lupus erythematosus (SLE) can involve many parts of the eye, including the eyelid, ocular adnexa, sclera, cornea, uvea, retina and optic nerve. Ocular manifestations of SLE are common and may lead to permanent blindness from the underlying disease or therapeutic side effects. Keratoconjunctivitis sicca is the most common manifestation. However, vision loss may result from involvement of the retina, choroid and optic nerve. Ocular symptoms are correlated to systemic disease activity and can present as an initial manifestation of SLE. The established treatment includes prompt systemic corticosteroids, steroid-sparing immunosuppressive drugs and biological agents. Local ocular therapies are options with promising efficacy. The early recognition of disease and treatment provides reduction of visual morbidity and mortality.

\section{INTRODUCTION}

Systemic lupus erythematosus (SLE) is a complex connective tissue disorder that involves multiple organs. Lupus erythematosus was first described and distinguished from lupus vulgaris by Cazenave and Schedel in 1833. In 1845, skin lesions were reported by Hebra and later biopsied in 1872 by Kaposi who also pointed to systemic symptoms. ${ }^{1}$ The first report of lupus in the eye was in 1929, and Semon and Wolff, in 1933, described the histopathological characteristics of choroiditis and subretinal exudation. ${ }^{2}$ Ocular involvement may correlate with systemic disease activity and precede other systemic symptoms stressing the important role the ophthalmologist may play. ${ }^{3}$

The reported prevalence of SLE in the population is $20-150$ cases per $100000 .^{4-6}$ The prevalence of SLE is different between age, gender, geographic and racial distributions. The female-to-male ratio is close to 9:1, and the estimated prevalence is $1 / 1000$ among American women above the age of $17 .^{7}$ Due to improved identification at mild disease stage and better approaches to therapy, the incidence of SLE has nearly tripled over the past four decades. ${ }^{9}$

\section{PATHOPHYSIOLOGY}

The pathogenesis of SLE is multifactorial and complex. Various genetic, epigenetic, immunoregulatory, environmental and infectious factors contribute to the susceptibility, onset, progression and prognosis of the clinical disease in a given patient. $^{3} 10$ The concordance rate has been reported between $24 \%$ and $57 \%$ in monozygotic twins, which outweighs the rate of $0-2 \%$ in dizygotic twins or siblings. ${ }^{11} 12$ Thirty-one susceptibility loci for SLE have been identified by genome-wide association studies and other gene mapping studies. ${ }^{13}$ Aberrant epigenetic regulation including DNA methylation, histone modifications and microRNA-mediated regulation may contribute to the complex array of immune abnormalities and disease manifestations in SLE. ${ }^{14}$

Inflammation in lupus is caused by the formation of autoantibodies and immune complexes and can cause inflammatory responses and activate the complement system. This results in multiorgan damage that manifests as nephritis, vasculitis and arthritis. ${ }^{3}$ Immunohistochemical studies of an animal model with retinal vasculitis disclosed immune complex deposition within the vessel walls, which ultimately caused vaso-occlusion in the eye. ${ }^{15}$ The key role of aberrant B cell autoreactivity in SLE was revealed in a landmark murine study using a knockout gene mutation to prevent lupus mice from developing B cells, which resulted in a lack of autoantibody formation and clinical manifestations (nephritis or vasculitis). ${ }^{16}$ Autoimmunity in SLE is a consequence of the progressive adaptive immune responses to autoantigens by not only B cells but also $\mathrm{T}$ cells. ${ }^{17}$ There are changes in T cells in patients with SLE, which cause increase in the proinflammatory Th17 cell population and decrease in the anti-inflammatory Tregulatory cell population. ${ }^{14}$

\section{DIAGNOSTIC CRITERIA}

The diagnostic criteria for SLE were developed by American College of Rheumatology (ACR). ${ }^{18} 19$ It was based on 4 of 11 criteria, either at the present time or at some time in the past; malar rash, discoid rash, photosensitivity, oral ulcers, non-erosive arthritis, serositis, renal disorder, neurological disorder (seizures or psychosis), haematological disorder (anaemia, leucopenia, thrombocytopenia), immunological disorder (anti-DNA antibody, anti-Sm antibody and false positive Venereal Disease Research Laboratory testing) and presence of antinuclear antibodies.

\section{OCULAR MANIFESTATIONS}

Ocular manifestations of SLE vary from patient to patient and can correlate to the systemic disease activity. Ocular involvement is moderately common in SLE and can be vision threatening. ${ }^{20}$ Findings may include abnormalities of the eyelid, ocular adnexa, keratoconjunctivitis sicca, iridocyclitis, retinal vasculitis, vaso-occlusive disorder, choroidopathy and optic neuropathy. Keratoconjunctivitis sicca is the most common manifestation while retinal and choroidal involvement are most associated with visual loss. ${ }^{21} 22$ Active inflammation in the retina and choroid can echo vasculitis in other organs, especially in cerebral vascular disease (table 1). ${ }^{23-27}$ In addition, though uncommon, 
Table 1 Association among lupus-related ocular posterior segment disorders to activity of systemic diseases and prognoses

\begin{tabular}{|c|c|c|c|c|c|c|c|}
\hline Authors & $\begin{array}{l}\text { Cases } \\
\text { (n) }\end{array}$ & Pathological site & Visual outcome & $\begin{array}{l}\text { Association to } \\
\text { systemic lupus }\end{array}$ & $\begin{array}{l}\text { Association to } \\
\text { CNS lupus }\end{array}$ & $\begin{array}{l}\text { Eye as an initial } \\
\text { manifestation }\end{array}$ & $\begin{array}{l}\text { Prognosis } \\
\text { for survival } \\
\text { (mortality rate) }\end{array}$ \\
\hline \multicolumn{8}{|l|}{ Case series } \\
\hline Frigui et $a l^{68}$ & 13 & Optic nerve & Moderate to poor & Positive & No & Yes & NA \\
\hline Lanham et $a /^{63}$ & 52 & $\begin{array}{l}\text { Retina (mostly } \\
\text { microangiopathy) }\end{array}$ & Good & Positive & No & No & NA \\
\hline Jabs et $a l^{26}$ & 11 & $\begin{array}{l}\text { Retina (mostly } \\
\text { vaso-occlusive cases) }\end{array}$ & Poor & Positive & Positive (73\%) & No & NA \\
\hline $\begin{array}{l}\text { Stafford-Brady } \\
\text { et } a l^{27}\end{array}$ & 550 & $\begin{array}{l}\text { Retina (mostly } \\
\text { microangiopathy) }\end{array}$ & Good & Positive (88\%) & Positive (73\%) & No & $\begin{array}{l}\text { Poor ( } 34 \% \text { died in } \\
16 \text { years } \\
\text { follow-up) }\end{array}$ \\
\hline Nguyen et $a l^{25}$ & 28 & Choroid & $\begin{array}{l}\text { Equivocal (improved } \\
\text { vision after resolved } \\
\text { choroidopathy) }\end{array}$ & Positive (100\%) & Positive (36\%) & Yes (1 case) & $14 \%$ \\
\hline Baglio et $a l^{78}$ & 16 & Choroid & NA & Positive (100\%) & NA & NA & NA \\
\hline \multicolumn{8}{|l|}{ Case reports } \\
\hline $\begin{array}{l}\text { Hwang and } \\
\text { Kang }^{56}\end{array}$ & 1 & $\begin{array}{l}\text { Retina (combined central } \\
\text { retinal vein and artery } \\
\text { occlusion) }\end{array}$ & NA & Positive & No & Yes & NA \\
\hline $\begin{array}{l}\text { Giocanti- } \\
\text { Auregan et al }\end{array}$ & 1 & Choroid & Poor & Positive & Positive & Yes & NA \\
\hline Wisotsky et $a^{60}$ & 1 & Choroid & NA & Positive & NA & Yes & NA \\
\hline
\end{tabular}

vision-threatening disease of the posterior segment involving the retina and optic nerve can precede systemic features and may aid in early diagnosis and prompt treatment of patients with SLE. ${ }^{28-30}$ Early diagnosis is the key to successful treatment and better prognosis.

\section{External eye diseases}

Orbit

Orbital involvement is a less common manifestation in SLE. Many case reports describe bilateral orbital involvement and unilateral periorbital involvement despite systemic nature of SLE. ${ }^{31-35}$ Inflammation manifesting as myositis and panniculitis has been described. ${ }^{32-3436}$ Patients may present with painful or painless proptosis, chemosis, ptosis, lid oedema or limited ocular movement. Inflammation can be confined to the orbit or spread to neighbouring tissues, which may lead to vision loss from optic neuropathy. ${ }^{35}$ Further biopsy, serological workup and long-term follow-up are essential to facilitate the proper diagnosis. $^{33}$

\section{Eyelid disorders}

Discoid lupus-type rash over the eyelids typically appears in the lower eyelid as an irritating, discrete, slightly raised erythematous scaly plaque, which can involve the lid margin and can be complicated by scarring and madarosis. ${ }^{31} 37$ Lid biopsy and direct immunohistochemistry studies are valuable in confirming the diagnosis. Topical corticosteroids and oral antimalarial drugs are typically effective. ${ }^{31} 37$

\section{Lacrimal system disorders}

Dry eye syndrome (keratoconjunctivitis sicca) is the most common ocular feature of SLE (around a third of patients) and is often associated with secondary Sjögren's syndrome (SS). ${ }^{38} 39$ The International Dry Eye Work Shop classified Sjögren's as an aqueous tear-deficient dry eye, reflecting failure of lacrimal tear secretion. Schirmer I test ( $\leq 5 \mathrm{~mm}$ in $5 \mathrm{~min}$ ) or rose bengal score
( $\geq 4$ according to van Bijsterveld's scoring system) are important tests for diagnosis of dry eye syndrome associated with SS. ${ }^{40}$ However, given patient discomfort after rose bengal instillation, lissamine green could be used as a substitute for rose bengal with similar staining patterns and greater tolerability to patients. $^{41}$

\section{Anterior segment diseases}

Corneal disorders

Corneal involvement in SLE involves the superficial epithelium manifesting as superficial punctate keratitis and may be secondary to SS. ${ }^{42}$ Peripheral ulcerative keratitis rarely occurs in SLE and is more commonly associated with rheumatoid arthritis. ${ }^{43}$ However, some cases of peripheral ulcerative keratitis have been reported in both non-infiltrative and infiltrative patterns. ${ }^{42}$

\section{Episclera and sclera}

Episcleritis is characterised by painless or mildly uncomfortable red eye with dilated episcleral vessels, which are non-tender and markedly reduced by topical phenylephrine. Unlike episcleritis, scleritis is a severe vision-threatening, progressively destructive inflammatory condition, which is more often associated with systemic disorders. Necrotising scleritis, though rare, is the type of scleritis most often associated with ocular complications and decreased vision. We reported a series of 585 patients with scleritis and episcleritis. We found that disease association was observed in $35.8 \%$ of patients with scleritis versus $27.1 \%$ of patients with episcleritis. ${ }^{44} \mathrm{~A}$ more recent analysis of 1358 cases of scleritis performed by Heron et $a l^{45}$ reported a $2 \%$ prevalence of SLE-associated scleritis compared with $6.4-10.4 \%$ of rheumatoid arthritis-related scleritis.

\section{Iridocyclitis}

There are few reports of iritis or iridocyclitis secondary to SLE particularly in adults. One adult case presented with bilateral keratitis and iridocyclitis and responded well to chloroquine. ${ }^{46}$ 
Nevertheless, visual deterioration is uncommon in isolated iritis. The inflammation in the anterior segment can present as hypopyon or fibrinous anterior uveitis. ${ }^{35} 47$ The inflammation in the anterior segment usually improves with the systemic immunosuppressants; however, atypical recalcitrant presentations have been reported to result in severe visual damage. ${ }^{47} 48$

\section{Posterior segment \\ Retinopathy}

Lupus retinopathy is a potentially blinding ocular manifestation of SLE. In the pre-steroid era, retinopathy was present in up to half of patients with SLE. ${ }^{49}$ However, with the advent of steroids and immunosuppressive therapy, the incidence of retinopathy has declined considerably. The prevalence of retinopathy varies among various populations, ranging from $3 \%$ in wellcontrolled patients to $29 \%$ of patients with more active systemic disease. ${ }^{50}$ Retinal involvement corresponded to activity of systemic and cerebral SLE (table 1). ${ }^{26} 275152$ The major pathology of lupus retinopathy is attributed to vasculopathy, most commonly, microangiopathy. It is thought to be an immune complex-mediated vasculopathy. ${ }^{15} 53$

The autoimmune process can affect the retina and choroid in two ways: directly, by immune complex-mediated vasculitis, and indirectly, by secondary hypertension from renal involvement. Hence, there are three types of direct retinal damage by lupus: microangiopathy, severe vaso-occlusion and vasculitis.

\section{Microangiopathy}

Microangiopathy should be considered the mild form of lupus retinopathy. The classic retinal findings are similar to diabetic and hypertensive retinopathy, including cotton wool spots, microaneurysms, hard exudates and dot haemorrhages. ${ }^{22} \quad 51$ Small intraretinal haemorrhages and cotton-wool spots account for $80 \%$ of cases and are usually associated with a good visual prognosis. $^{27}$

\section{Severe vaso-occlusion}

This most severe form of lupus retinopathy manifests within a wide spectrum of ischaemia, from occlusion in major vessels like central retinal vessels and cilioretinal artery to extensive microembolisation in small vessels presenting as Purtscher-like retinopathy.

Severe vaso-occlusive retinopathy is a rare but well-described entity that is associated with widespread retinal capillary nonperfusion, multiple branch retinal artery occlusions, ocular neovascularisation, vitreous haemorrhage, tractional retinal detachment, neovascular glaucoma and significant resultant visual loss (figure 1). ${ }^{545}$ Central retinal vein or artery occlusions can also occur, either independently or together, and may be unilateral or bilateral. ${ }^{54}{ }^{56-59}$ A study by Jabs et $a l^{26}$ disclosed 55\% of eyes with severe retinal vaso-occlusive disease suffered vision loss, often due to a visual acuity of worse than 20/200. A recent report of Purtscher-like retinopathy of 8 from 5688 patients with SLE revealed an association between Purtscher-like retinopathy with central nervous system lupus and highly active disease. Visual acuity recovery was usually poor despite prompt treatment. $^{52}$

\section{Vasculitis}

The terminology of 'vasculitis' in lupus retinopathy can be confounding among clinical presentation and pathogenesis. Though immune complex deposition leading to complement activation is well known in lupus retinopathy, clinically presenting vasculitis is fairly uncommon. The classic sign of vasculitis is vascular sheathing, which can present in arterioles and/or venules. Vaso-occlusion is a common end-point of vasculitis that may alter visual function (figure 2).

Renal involvement by SLE will generally lead to secondary hypertension. When prolonged, it usually affects retina and choroid and is characterised by retinal arterial narrowing, arteriovenous crossing changes, microaneurysms, intraretinal haemorrhages, hard exudates, disc oedema and multifocal serous or pigment epithelial detachment.

\section{Choroidopathy}

Lupus choroidopathy can occur either independently or with lupus retinopathy and may present with good visual acuity. Nguyen et al reported a total of 28 patients with lupus choroidopathy and found $64 \%$ of presenting visual acuity of $20 / 40$ or better. The common manifestations include single or multiple areas of serous or exudative retinal detachment (36\%), detachment of the retinal pigment epithelium $(32 \%)$ or retinal pigment epitheliopathy $(21 \%) .^{25}$ Choroidal ischaemia can present as subretinal hypopigmented patches and angiography can help confirm ischaemic areas (figure 3). Secondary angleclosure glaucoma has also been reported secondary to choroidal effusion, leading to an anterior shift of the lens-iris diaphragm, narrow angles and increased intraocular pressure. ${ }^{60} 61$ Appropriate immunosuppressive treatment leads to resolution of lupus choroidopathy followed by recovered vision. ${ }^{3} 25$

\section{Imaging in lupus retinopathy and choroidopathy}

Modern imaging techniques including fundus fluorescein angiography (FFA), indocyanine green (ICG) and optical coherent tomography (OCT) have played an important role in the evaluation and monitoring of lupus retinopathy and choroidopathy.
Figure 1 Fundus photograph (left) and fluorescein angiogram (right) of a 54-year-old woman who presented with acute severe vision loss in both eyes. Fundus photo (left) and angiogram (right) note extensive retinal capillary non-perfusion and macular ischaemia. Oral prednisone and anticoagulant were employed without steroid-sparing immunosuppressant. Final visual acuity was no light perception in 3 months later.

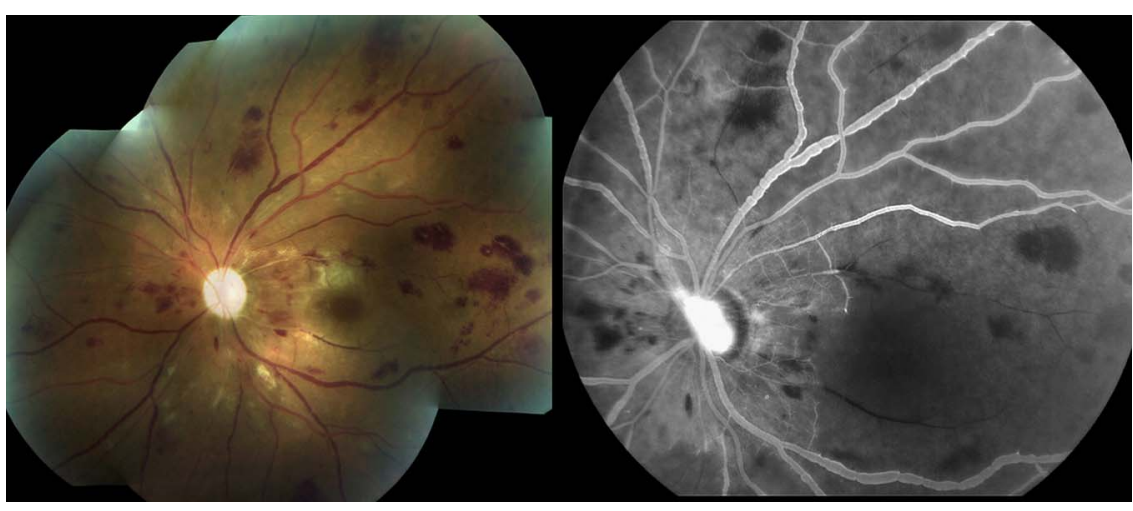


Figure 2 Fundus photograph (left) and early-phase fluorescein angiogram (right) of a 37-year-old woman who previously presented with lupus retinal vasculitis and was treated with scattered laser photocoagulation in 2006. Significant hyperfluorescent leakage represented the recurrence of neovascularisation. She received oral prednisone, methotrexate and intravenous cyclophosphamide. Initial visual acuity and visual acuity 8 years later were 20/60 and 20/100, respectively.

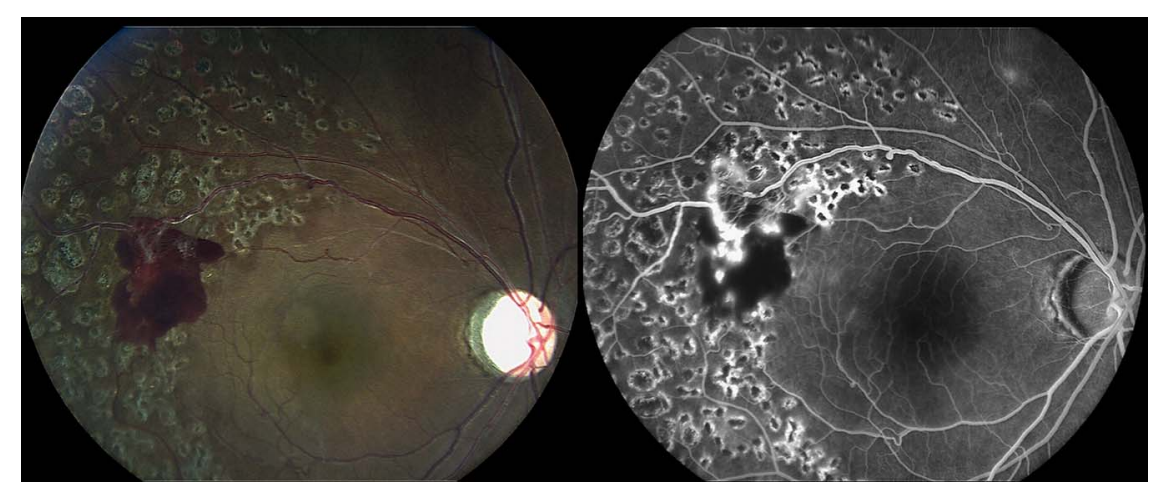

FA findings may help identify subclinical findings in patients with SLE, manifesting as leakage, retinal capillary dilatation and microaneurysms in patients with mild-to-moderate disease activity. ${ }^{62} 63$ Choroidal pathology can also be studied with FFA by identifying delayed choroidal filling, areas of choroidal nonperfusion (figure 3) or multifocal areas of subretinal leakage with pooling corresponding to the areas of serous elevation and inferior retinal detachment. $^{25}$

ICG can help to identify active choroidopathy not seen on clinical examination or FFA. It may detect focal, transient hypofluorescent areas in the early phase and spots of choroidal hyperfluorescence in the intermediate to late phase. Interestingly, pinpoint spots of ICG choroidal hyperfluorescence may represent immune deposition in deeper layer of choroidal stroma or Bruch membrane. ${ }^{64}$

OCT offers a non-invasive way to follow the structural changes of SLE. Its advantage is apparent, especially in active phase of disease identifying intraretinal and subretinal fluid and pigment epithelial detachment with ease. The qualitative and quantitative evaluations of OCT are also beneficial in diagnosis and monitoring of lupus choroidopathy. ${ }^{65} 66$

\section{Neuro-ophthalmological manifestations}

Neuro-ophthalmic manifestations of lupus are not common. The prevalence is $3.6 \%$ in adults and $1.6 \%$ in children. Findings are highly variable, with the most common presentation being optic neuritis, followed by myasthenia gravis, visual field defects and optic disc oedema. ${ }^{67}$ Optic neuropathy, which may manifest as the presenting feature of disease, ${ }^{68}$ is the most common finding and occurs in about $1 \%$ of patients with SLE $^{22} 67$ (table 1). Initial visual loss can be severe in SLE-associated optic neuritis, causing no light perception vision. ${ }^{69} 70$ Presentations can vary based on the location of pathology. Patients may present with painless or painful progressive visual loss, with or without pain on eye movement, optic disc swelling or pallor on examination. ${ }^{506869}$ Optic neuritis generally responds well to corticosteroid treatment. Visual prognosis following optic neuropathy is generally moderate to poor, although good outcomes have been reported. ${ }^{68}{ }^{69}$ In addition, for patients with SLE with suspected optic neuritis and relapsing myelitis, testing for the aquaporin-4 autoantibody would help confirm the correct diagnosis of neuromyelitis optica. ${ }^{71} 72$ Ischaemic optic neuropathy ${ }^{73} 74$ and chiasmopathy ${ }^{69}$ in SLE have also been described.

Eye movement abnormalities are more common in SLE and have been reported in up to $29 \%$ of patients. ${ }^{75}$ Pseudotumor cerebri has been reported in both children and adults with SLE, and may be the presenting feature of the disease. ${ }^{76} 77$

\section{PROGNOSIS AND SYSTEMIC ASSOCIATIONS}

Table 1 shows association among lupus-related ocular posterior segment disorders and systemic involvement including activity and prognosis. Visual prognosis of retinal involvement depends on pattern of retinopathy, and vaso-occlusion usually leads to poor visual outcome. Two reviews of retinopathy and choroidopathy pointed out that these two entities are indicative of guarded to poor survival. ${ }^{25} 27$ Unlike demyelinating processes in which association between optic neuritis and brain is common, a review of SLE presenting as optic neuropathy revealed no association to CNS disorder. ${ }^{68}$ This may reflect and support the ischaemic aetiology of SLE-related neuro-ophthalmological disorders.
Figure 3 Fundus photograph (left) 46-year-old woman diagnosed with lupus-associated catastrophic antiphospholipid syndrome with bilateral choroidal infarction and uveitis. Image from the right eye demonstrates unremarkable retinal vasculature and distinct geographic subretinal patches. These hypopigmented patches correspond to extensive absence of choroid filling pattern in angiogram. Given intravenous methylprednisolone, rituximab and anticoagulant, the patient maintained visual acuity of 20/600 5 years later. and fluorescein angiogram (right) of a

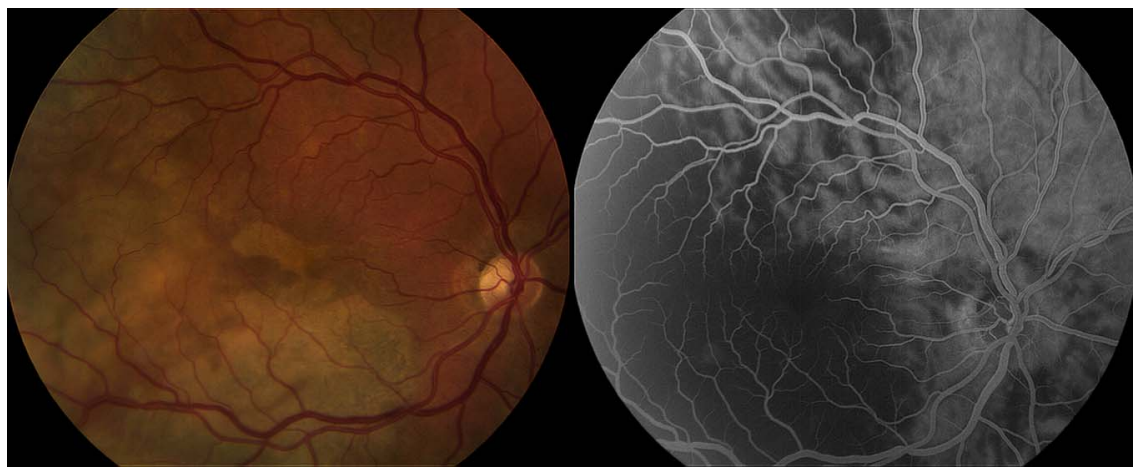




\section{Treatment}

The heterogeneous nature and multisystem involvement make treatment of SLE difficult. Nevertheless, the general goals of therapy are to induce and maintain remission of the disease, and prevent relapses. Proper management requires a team approach that may include specialists in the fields of rheumatology, nephrology, dermatology and ophthalmology. Treatment strategies for SLE include non-steroidal anti-inflammatory drugs, hydroxychloroquine, systemic corticosteroids, immunosuppressive therapy and biologics. The effective immunosuppressive drugs include azathioprine, methotrexate, mycophenolate mofetil and cyclophosphamide. Increasingly, patients with lupus who do not respond to conventional immunosuppressive drugs are considered for targeted biological therapies aimed at cytokines, B and $\mathrm{T}$ lymphocytes, and B-cell-activating factors. Rituximab, B-cell-depleting therapy, has been used when conventional drugs have proven ineffective. ${ }^{80}$ Combination of rituximab and cyclophosphamide infusions employed early in the course of retinal vasculitis and vaso-occlusive disease also granted rapid resolution as well as dramatic improvement in vision. ${ }^{81}$ Belimumab, a monoclonal human antibody that inactivates B-cell-activating factor, is the first biologic recently approved by the US Food and Drug Administration after 50 years as an add-on therapy for active SLE. ${ }^{80} 82$ In addition, epratuzumab and sifalimumab, biological response modifiers currently being investigated, also showed positive outcome. The treatment of CD22-targeted monoclonal antibody epratuzumab in adults with moderately to severely active SLE was reportedly associated with improvements in disease activity. ${ }^{83}$ Sifalimumab, a human anti-interferon- $\alpha$ monoclonal antibody, was proven to be safe, and clinical activity profile supports its continued clinical development for SLE. ${ }^{80}$

Hydroxychloroquine is an effective medication for SLE. It is now recommended long term for all patients with SLE. ${ }^{84}$ Correlation between discontinuation of chloroquine and retinal vaso-occlusion was described by el-Asrar et al. ${ }^{57}$ Patients must be made aware of the possible risk of macular toxicity and have regular eye check-up to monitor for this complication. ${ }^{85}$

Local treatment also plays an important role in treatment of recalcitrant intraocular inflammation. Ocular findings in SLE are not specific and share common manifestations with other systemic diseases, such as lupus scleritis and rheumatoid scleritis, lupus retinopathy with hypertensive and diabetic retinopathy. As such, local treatment strategies should be tailored to the specific pathology. Laser photocoagulation has been known as standard treatment in ischaemic retinal disorders such as diabetic retinopathy and ischaemic retinal vascular occlusion. Panretinal photocoagulation showed promising efficacy in regression of neovascularisation before the antivascular endothelial growth factor (anti-VEGF) era. ${ }^{54}$ However, the administration of immunosuppressants and panretinal photocoagulation (PRP) was insufficient to prevent the neovascularisation process in many case reports. 548687

VEGF plays a vital role in inflammatory processes and in the pathogenesis of uveitic complications such as cystoid macular oedema, choroidal neovascularisation and retinal neovascularisation (RNV). ${ }^{88}$ The VEGF serum concentration in patients with SLE was significantly higher than healthy controls and may be a useful marker of disease activity and internal organ involvement in patients with SLE. ${ }^{89}$ 90 Recently, anti-VEGF has been reported as a powerful tool for vaso-occlusion and vasculitis in patients with lupus. It showed efficacy in regressing RNV even after employment of immunosuppressive treatment and PRP. $^{86}{ }^{87}$ While VEGF inhibition seems reasonable to treat RNV, the role of anti-VEGF therapy to treat inflammation is less clear and needs to be investigated. ${ }^{88}$ Repeat anti-VEGF injections in vaso-occlusion with macular ischaemia should be performed only if monitoring FFA can be done to prevent worsening of macular ischaemia. Finally, vitrectomy can also be helpful in complicated neovascularisation, vitreous haemorrhage and traction retinal detachment. ${ }^{5486}$

\section{Future direction}

The future of SLE consists of newly emerging agents that specifically target mechanisms involved in the pathogenesis of SLE and biomarkers allow physicians to adopt theranostics, a patient-tailored approach. Hopefully in the future systemic glucocorticoids will be used less and gradually replaced by early commencement of other immunosuppressive or biological therapies. Among a myriad of emerging biological agents, the ones with positive outcomes in literature are belimumab, rituximab, epratuzumab and sifalimumab. In spite of failure of a major trial, rituximab has been considered for patients with active lupus nephritis refractory to conventional therapies by the ACR and the European League Against Rheumatism. ${ }^{80}$ Early treatment with rituximab showed promising efficacy and safety in newly diagnosed SLE. ${ }^{91}$ The success of belimumab encourages other studies of molecules that block B-cell-activating factors. Both belimumab and rituximab have also provided support in the maintenance phase of lupus nephritis. ${ }^{92} 93$ Better insight in the mechanisms and accountable biomarkers of inflammation will bring about more acceptable diagnostic criteria and successful treatment strategies. Treatment of ocular disease in SLE is based on systemic therapy. As such, local ocular therapy in lupus is not widely investigated. While PRP still serves as an effective treatment for neovascularisation sequel, anti-VEGF therapy has showed additional benefit in refractory cases.

\section{Competing interests None declared.}

Provenance and peer review Not commissioned; externally peer reviewed.

\section{REFERENCES}

1 Hebra F, Kaposi M. On diseases of the skin, including the exanthemata. London: The New Sydenham Society, 1875

2 Semon HC, Wolff E. Acute Lupus Erythematosus, with Fundus Lesions. Proc $R$ Soc Med 1933;27:153-7.

3 Foster CS, Vitale AT. Diagnosis and treatment of uveitis. 2 edn. Jaypee Brothers Medical Publishers, 2013

4 Lawrence RC, Helmick CG, Arnett FC, et al. Estimates of the prevalence of arthritis and selected musculoskeletal disorders in the United States. Arthritis Rheum 1998:41:778-99.

5 Chakravarty EF, Bush TM, Manzi S, et al. Prevalence of adult systemic lupus erythematosus in California and Pennsylvania in 2000: estimates obtained using hospitalization data. Arthritis Rheum 2007:56:2092-4.

6 Pons-Estel GJ, Alarcon GS, Scofield L, et al. Understanding the epidemiology and progression of systemic lupus erythematosus. Semin Arthritis Rheum 2010;39:257-68

7 Mills JA. Systemic lupus erythematosus. N Engl J Med 1994;330:1871-9.

8 Ward MM. Prevalence of physician-diagnosed systemic lupus erythematosus in the United States: results from the third national health and nutrition examination survey. J Womens Health (Larchmt) 2004;13:713-18.

9 Uramoto KM, Michet CJ Jr, Thumboo J, et al. Trends in the incidence and mortality of systemic lupus erythematosus, 1950-1992. Arthritis Rheum 1999;42:46-50.

10 Esen BA, Yilmaz G, Uzun S, et al. Serologic response to Epstein-Barr virus antigens in patients with systemic lupus erythematosus: a controlled study. Rheumatol Int 2012;32:79-83

11 Block SR, Winfield JB, Lockshin MD, et al. Studies of twins with systemic lupus erythematosus. A review of the literature and presentation of 12 additional sets. Am J Med 1975;59:533-52.

12 Deapen D, Escalante A, Weinrib $L$, et al. A revised estimate of twin concordance in systemic lupus erythematosus. Arthritis Rheum 1992;35:311-18.

13 Deng Y, Tsao BP. Genetic susceptibility to systemic lupus erythematosus in the genomic era. Nat Rev Rheumatol 2010;6:683-92. 
14 Konya C, Paz Z, Tsokos GC. The role of T cells in systemic lupus erythematosus: an update. Curr Opin Rheumatol 2014;26:493-501.

15 Levine RA, Ward PA. Experimental acute immunologic ocular vasculitis. Am J Ophthalmol 1970;69:1023-31.

16 Kamal A, Khamashta M. The efficacy of novel B cell biologics as the future of SLE treatment: a review. Autoimmun Rev 2014;13:1094-101.

17 Marion TN, Postlethwaite AE. Chance, genetics, and the heterogeneity of disease and pathogenesis in systemic lupus erythematosus. Semin Immunopathol 2014;36:495-517.

18 Tan EM, Cohen AS, Fries JF, et al. The 1982 revised criteria for the classification of systemic lupus erythematosus. Arthritis Rheum 1982;25:1271-7.

19 Yu C, Gershwin ME, Chang C. Diagnostic criteria for systemic lupus erythematosus: a critical review. J Autoimmun 2014;48-49:10-13.

20 Peponis V, Kyttaris VC, Tyradellis C, et al. Ocular manifestations of systemic lupus erythematosus: a clinical review. Lupus 2006;15:3-12.

21 Palejwala NV, Walia HS, Yeh S. Ocular manifestations of systemic lupus erythematosus: a review of the literature. Autoimmune Dis 2012;2012:290898.

22 Sivaraj RR, Durrani OM, Denniston AK, et al. Ocular manifestations of systemic lupus erythematosus. Rheumatology (Oxford) 2007:46:1757-62.

23 Md Noh UK, Zahidin AZ, Yong TK. Retinal vasculitis in systemic lupus erythematosus: an indication of active disease. Clin Pract 2012;2:e54

24 Graham EM, Spalton DJ, Barnard RO, et al. Cerebral and retinal vascular changes in systemic lupus erythematosus. Ophthalmology 1985;92:444-8.

25 Nguyen QD, Uy HS, Akpek EK, et al. Choroidopathy of systemic lupus erythematosus. Lupus 2000;9:288-98.

26 Jabs DA, Fine SL, Hochberg MC, et al. Severe retinal vaso-occlusive disease in systemic lupus erythematous. Arch Ophthalmol 1986;104:558-63.

27 Stafford-Brady FJ, Urowitz MB, Gladman DD, et al. Lupus retinopathy. Patterns, associations, and prognosis. Arthritis Rheum 1988;31:1105-10.

28 Bandyopadhyay SK, Moulick A, Dutta A. Retinal vasculitis--an initial presentation of systemic lupus erythematosus. J Indian Med Assoc 2006;104:526-7.

29 Barkeh HJ, Muhaya M. Optic neuritis and retinal vasculitis as primary manifestations of systemic lupus erythematosus. Med J Malaysia 2002;57:490-2.

30 Song YH, Kim CG, Kim SD, et al. Systemic lupus erythematosus presenting earlier as retinal vaso-occlusion. Korean J Intern Med 2001;16:210-13.

31 Ghauri AJ, Valenzuela AA, O'Donnell B, et al. Periorbital discoid lupus erythematosus. Ophthalmology 2012;119:2193-4.

32 Santosa A, Vasoo S. Orbital myositis as manifestation of systemic lupus erythematosus--a case report. Postgrad Med J 2013;89:59.

33 Ohsie LH, Murchison AP, Wojno TH. Lupus erythematosus profundus masquerading as idiopathic orbital inflammatory syndrome. Orbit 2012;31:181-3.

34 Kono S, Takashima H, Suzuki D, et al. Orbital myositis associated with discoid lupus erythematosus. Lupus 2014:23:220-2.

35 Stavrou P, Murray PI, Batta K, et al. Acute ocular ischaemia and orbital inflammation associated with systemic lupus erythematosus. $\mathrm{Br} J$ Ophthalmol 2002;86:474-5.

36 Serop S, Vianna RN, Claeys M, et al. Orbital myositis secondary to systemic lupus erythematosus. Acta Ophthalmol (Copenh) 1994;72:520-3.

37 Mseddi M, Marrekchi S, Meziou TJ, et al. [Discoid lupus erythematosus with eyelid involvement. A series of nine patients]. J Fr Ophtalmol 2007;30: 247-9.

38 Read RW. Clinical mini-review: systemic lupus erythematosus and the eye. Ocul Immunol Inflamm 2004;12:87-99.

39 Jensen JL, Bergem HO, Gilboe IM, et al. Oral and ocular sicca symptoms and findings are prevalent in systemic lupus erythematosus. I Oral Pathol Med 1999;28:317-22

40 [No authors listed]. The definition and classification of dry eye disease: report of the Definition and Classification Subcommittee of the International Dry Eye WorkShop (2007). Ocul Surf 2007;5:75-92.

41 Machado LM, Castro RS, Fontes BM. Staining patterns in dry eye syndrome: rose bengal versus lissamine green. Cornea 2009;28:732-4.

42 Messmer EM, Foster CS. Vasculitic peripheral ulcerative keratitis. Surv Ophthalmol 1999:43:379-96.

43 Knox Cartwright NE, Tole DM, Georgoudis P, et al. Peripheral ulcerative keratitis and corneal melt: a 10-year single center review with historical comparison. Cornea 2014:33:27-31.

44 Sainz de la Maza M, Molina N, Gonzalez-Gonzalez LA, et al. Clinical characteristics of a large cohort of patients with scleritis and episcleritis. Ophthalmology 2012;119:43-50.

45 Heron E, Gutzwiller-Fontaine M, Bourcier T. Scleritis and episcleritis: diagnosis and treatment. Rev Med Interne 2014;35:577-85.

46 Halmay 0, Ludwig K. Bilateral band-shaped deep keratitis and iridocyclitis in systemic lupus erythematosus. Br J Ophthalmol 1964;48:558-62.

47 Zink JM, Singh-Parikshak R, Johnson CS, et al. Hypopyon uveitis associated with systemic lupus erythematosus and antiphospholipid antibody syndrome. Graefes Arch Clin Exp Ophthalmol 2005;243:386-8.

48 Almeida RT, Aikawa NE, Sallum AM, et al. Irreversible blindness in juvenile systemic lupus erythematosus. Lupus 2011;20:95-7.
49 Baehr G, Klemperer P, Schifrin A. A diffuse disease of the peripheral circulation (usually associated with lupus erythematosus and endocarditis). Am J Med 1952;13:591-6.

50 Davies JB, Rao PK. Ocular manifestations of systemic lupus erythematosus. Curr Opin Ophthalmol 2008;19:512-18.

51 Ushiyama 0, Ushiyama K, Koarada S, et al. Retinal disease in patients with systemic lupus erythematosus. Ann Rheum Dis 2000;59:705-8.

52 Wu C, Dai R, Dong F, et al. Purtscher-like retinopathy in systemic lupus erythematosus. Am I Ophthalmol 2014;158:1335-41.

53 Aronson AJ, Ordonez NG, Diddie KR, et al. Immune-complex deposition in the eye in systemic lupus erythematosus. Arch Intern Med 1979;139:1312-13.

54 Au A, O'Day J. Review of severe vaso-occlusive retinopathy in systemic lupus erythematosus and the antiphospholipid syndrome: associations, visual outcomes, complications and treatment. Clin Experiment Ophthalmol 2004;32:87-100.

55 Read RW, Chong LP, Rao NA. Occlusive retinal vasculitis associated with systemic lupus erythematosus. Arch Ophthalmol 2000;118:588-9.

56 Hwang HS, Kang S. Combined central retinal vein and artery occlusion in systemic lupus erythematosus patient. Retin Cases Brief Rep 2012;6:187-8.

57 el-Asrar AM, Naddaf HO, al-Momen AK, et al. Systemic lupus erythematosus flare-up manifesting as a cilioretinal artery occlusion. Lupus 1995;4:158-60.

58 Chang PC, Chen WS, Lin HY, et al. Combined central retinal artery and vein occlusion in a patient with systemic lupus erythematosus and anti-phospholipid syndrome. Lupus 2010;19:206-9.

59 Durukan AH, Akar Y, Bayraktar MZ, et al. Combined retinal artery and vein occlusion in a patient with systemic lupus erythematosus and antiphospholipid syndrome. Can J Ophthalmol 2005;40:87-9.

60 Wisotsky BJ, Magat-Gordon CB, Puklin JE. Angle-closure glaucoma as an initial presentation of systemic lupus erythematosus. Ophthalmology 1998;105:1170-2.

61 Lavina AM, Agarwal A, Hunyor A, et al. Lupus choroidopathy and choroidal effusions. Retina 2002;22:643-7.

62 Santos $R$, Barojas E, Alarcon-Segovia $D$, et al. Retinal microangiopathy in systemic lupus erythematosus. Am J Ophthalmol 1975;80:249-52.

63 Lanham JG, Barrie T, Kohner EM, et al. SLE retinopathy: evaluation by fluorescein angiography. Ann Rheum Dis 1982;41:473-8.

64 Gharbiya M, Pecci G, Baglio V, et al. Indocyanine green angiographic findings for patients with systemic lupus erythematosus nephropathy. Retina 2006;26: 159-64.

65 Ozturk B, Bozkurt B, Karademir Z, et al. Follow-up of lupus choroidopathy with optical coherence tomography. Lupus 2011;20:1076-8.

66 Kouprianoff S, Chiquet C, Bouillet L, et al. OCT follow-up of systemic lupus erythematosus choroidopathy. Ocul Immunol Inflamm 2010;18:113-15.

67 Man BL, Mok CC, Fu YP. Neuro-ophthalmologic manifestations of systemic lupus erythematosus: a systematic review. Int I Rheum Dis 2014;17:494-501.

68 Frigui $M$, Frikha F, Sellemi $D$, et al. Optic neuropathy as a presenting feature of systemic lupus erythematosus: two case reports and literature review. Lupus 2011;20:1214-18.

69 Siatkowski RM, Scott IU, Verm AM, et al. Optic neuropathy and chiasmopathy in the diagnosis of systemic lupus erythematosus. J Neuroophthalmol 2001;21: 193-8.

70 Lin YC, Wang AG, Yen MY. Systemic lupus erythematosus-associated optic neuritis: clinical experience and literature review. Acta Ophthalmol 2009;87:204-10.

71 Jarius S, Wildemann B. Aquaporin-4 antibodies (NMO-lgG) as a serological marker of neuromyelitis optica: a critical review of the literature. Brain Pathol 2013;23:661-83.

72 Zavada J, Nytrova P, Wandinger KP, et al. Seroprevalence and specificity of NMO-IgG (anti-aquaporin 4 antibodies) in patients with neuropsychiatric systemic lupus erythematosus. Rheumatol Int 2013;33:259-63.

73 Cordeiro MF, Lloyd ME, Spalton DJ, et al. Ischaemic optic neuropathy, transverse myelitis, and epilepsy in an anti-phospholipid positive patient with systemic lupus erythematosus. J Neurol Neurosurg Psychiatry 1994;57:1142-3.

74 Massin M, Berche C, Ullern M, et al. Acute anterior ischemic optic neuropathy disclosing disseminated lupus erythematosus. Ophtalmologie 1987;1:61-3.

75 Keane JR. Eye movement abnormalities in systemic lupus erythematosus. Arch Neurol 1995:52:1145-9.

76 Carlow TJ, Glaser JS. Pseudotumor cerebri syndrome in systemic lupus erythematosus. JAMA 1974;228:197-200.

77 DelGiudice GC, Scher CA, Athreya BH, et al. Pseudotumor cerebri and childhood systemic lupus erythematosus. J Rheumatol 1986;13:748-52.

78 Baglio V, Gharbiya M, Balacco-Gabrieli C, et al. Choroidopathy in patients with systemic lupus erythematosus with or without nephropathy. I Nephrol 2011;24:522-9.

79 Giocanti-Auregan A, Grenet T, Rohart C, et al. Inaugural severe vaso-occlusive retinopathy in systemic lupus erythematosus. Int Ophthalmol 2013;33:323-6.

80 Lisnevskaia L, Murphy G, Isenberg D. Systemic lupus erythematosus. Lancet 2014;384:1878-88.

81 Donnithorne KJ, Read RW, Lowe R, et al. Retinal vasculitis in two pediatric patients with systemic lupus erythematosus: a case report. Pediatr Rheumatol Online J 2013;11:25. 
82 Specchia ML, de Waure C, Gualano MR, et al. Health technology assessment of belimumab: a new monoclonal antibody for the treatment of systemic lupus erythematosus. Biomed Res Int 2014;2014:704207.

83 Wallace DJ, Kalunian K, Petri MA, et al. Efficacy and safety of epratuzumab in patients with moderate/severe active systemic lupus erythematosus: results from EMBLEM, a phase Ilb, randomised, double-blind, placebo-controlled, multicentre study. Ann Rheum Dis 2014;73:183-90.

84 Tang C, Godfrey T, Stawell R, et al. Hydroxychloroquine in lupus: emerging evidence supporting multiple beneficial effects. Intern Med J 2012;42:968-78.

85 Mavrikakis I, Sfikakis PP, Mavrikakis E, et al. The incidence of irreversible retinal toxicity in patients treated with hydroxychloroquine: a reappraisal. Ophthalmology 2003:110:1321-6.

86 Lee WJ, Cho HY, Lee YJ, et al. Intravitreal bevacizumab for severe vasoocclusive retinopathy in systemic lupus erythematosus. Rheumatol Int 2013;33: 247-51.

87 Kurup S, Lew J, Byrnes G, et al. Therapeutic efficacy of intravitreal bevacizumab on posterior uveitis complicated by neovascularization. Acta Ophthalmol 2009;87:349-52.
88 Gulati N, Forooghian F, Lieberman R, et al. Vascular endothelial growth factor inhibition in uveitis: a systematic review. Br J Ophthalmol 2011;95:162-5.

89 Moneib HA, Salem SA, Aly DG, et al. Assessment of serum vascular endothelial growth factor and nail fold capillaroscopy changes in systemic lupus erythematosus with and without cutaneous manifestations. J Dermatol 2012;39:52-7.

90 Kuryliszyn-Moskal A, Klimiuk PA, Sierakowski S, et al. Vascular endothelial growth factor in systemic lupus erythematosus: relationship to disease activity, systemic organ manifestation, and nailfold capillaroscopic abnormalities. Arch Immunol Ther Exp (Warsz) 2007;55:179-85.

91 Ezeonyeji AN, Isenberg DA. Early treatment with rituximab in newly diagnosed systemic lupus erythematosus patients: a steroid-sparing regimen. Rheumatology (Oxford) 2012;51:476-81.

92 Dooley MA, Houssiau F, Aranow C, et al. Effect of belimumab treatment on renal outcomes: results from the phase 3 belimumab clinical trials in patients with SLE. Lupus 2013;22:63-72.

93 Pepper R, Griffith M, Kirwan C, et al. Rituximab is an effective treatment for lupus nephritis and allows a reduction in maintenance steroids. Nephrol Dial Transplant 2009;24:3717-23. 